\title{
PENGARUH KEPEMIMPINAN TRANSFORMASIONAL TERHADAP KINERJA KARYAWAN DENGAN OCB SEBAGAI VARIABEL MEDIASI
}

\author{
Devi Shinta Prahesti ${ }^{1}$ \\ I Gede Riana ${ }^{2}$ \\ I Made Artha Wibawa ${ }^{3}$
}

${ }^{1,2,3}$ Fakultas Ekonomi dan Bisnis Universitas Udayana (Unud), Bali, Indonesia e-mail: devibirgita@gmail.com

\begin{abstract}
ABSTRAK
Tujuan penelitian ini adalah untuk menganalisis dan menjelaskan peran mediasi organizational citizenship behavior pada hubungan kepemimpinan transformasional terhadap kinerja karyawan koperasi di Tabanan. Populasi penelitian adalah karyawan koperasi di kecamatan Tabanan dengan jumlah sampel adalah 114 responden pada 25 koperasi. Teknik pengambilan sampel dilakukan adalah teknik sampling acak sederhana. Instrumen penelitian menggunakan kuesioner dan metode analisis menggunakan Partial Least Square (PLS) dengan software SmartPLS 2.0. Hasil penelitian menunjukkan (1) kepemimpinan transformasional berpengaruh positif dan signifikan terhadap $O C B$ (2) kepemimpinan transformasional berpengaruh positif dan signifikan terhadap kinerja karyawan (3) $O C B$ berpengaruh positif dan signifikan terhadap kinerja karyawan (4) $O C B$ memediasi secara parsial dan positif serta signifikan hubungan antara kepemimpinan transformasionaldan kinerja karyawan. Implikasi hasil penelitian ini menunjukkan bahwa kepemimpinan transformasional ditemukan sebagai faktor utama dalam meningkatkan kinerja karyawan. Saran pada penelitian yaitu perluasan orientasi penelitian pada lingkup industri dan organisasi yang lebih luas untuk memproleh hasil yang lebih komperehensif.
\end{abstract}

Kata Kunci: Kepemimpinan Transformasional, $O C B$, Kinerja Karyawan

\begin{abstract}
The purpose of this study is to analyze and explain the mediating role of organizational citizenship behavior on the relationship of transformational leadership on employee performance of cooperatives in Tabanan. The study population were employees of cooperatives in the district of Tabanan with a sample size is 114 respondents in 25 cooperatives. The sampling technique is done by simple random sampling technique. The research instrument used questionnaire and analysis methods using Partial Least Square (PLS) with software SmartPLS 2.0. The results showed (1) transformational leadership has a positive and significant effect on $O C B(2)$ transformational leadership has a positive and significant effect on employee performance (3) OCB has a positive and significant effect on the performance of employees (4) OCB mediate partially and positive and significant relationship between leadership transformasional and employee performance. The implication of this study indicated that transformational leadership was found as a major factor in improving employee performance.. Suggestions for the results are expand the orientation research in wider scope industry and organization to reach more obtain results.
\end{abstract}

Keywords: Transformational Leadership, OCB, Employee Performance 


\section{PENDAHULUAN}

Koperasi merupakan salah satu pendorong pertumbuhan ekonomi yang berbasis ekonomi kerakyatan. Koperasi merupakan badan usaha yang dimiliki dan dioperasikan oleh seorang atau beberapa orang demi kepentingan anggota (Juniantara, 2015). Perkembangan koperasi saat ini didukung oleh perkembangan usaha kecil dan menengah (UKM) di Bali dan khususnya di Kota Tabanan yang semakin pesat. Hal ini dibuktikan dengan jumlah koperasi baru dan jumlah keanggotaan koperasi di Tabanan dari tahun 2011 - 2015 yang terus mengalami peningkatan.

Tabel 1.

Perkembangan Koperasi di Tabanan Tahun 2011-2015

\begin{tabular}{ccccccc}
\hline Tahun & Aktif & $\begin{array}{c}\text { Tidak } \\
\text { Aktif }\end{array}$ & Total & $\begin{array}{c}\text { Anggota } \\
\text { (orang) }\end{array}$ & $\begin{array}{c}\text { Aset } \\
\text { (rupiah) }\end{array}$ & $\begin{array}{c}\text { SHU } \\
\text { (rupiah) }\end{array}$ \\
\hline $\mathbf{2 0 1 1}$ & 446 & 47 & 493 & 73.000 & 462.298 .000 .000 & 8.070 .000 .000 \\
$\mathbf{2 0 1 2}$ & 468 & 47 & 515 & 74.217 & 658.369 .000 .000 & 9.558 .000 .000 \\
$\mathbf{2 0 1 3}$ & 478 & 53 & 531 & 78.044 & 708.044 .000 .000 & 12.460 .000 .000 \\
$\mathbf{2 0 1 4}$ & 488 & 50 & 538 & 79.781 & 890.216 .619 .000 & 15.971 .476 .000 \\
$\mathbf{2 0 1 5}$ & 506 & 43 & 549 & 83.766 & 1.233 .724 .994 .985 & 21.976 .033 .111 \\
\hline
\end{tabular}

Sumber: Dinas Koperasi UMKM Kabupaten Tabanan, 2015

Pengelolaan koperasi tidak cukup hanya dengan dana yang besar, tetapi harus ditunjang dengan pola pembinaan yang intensif, terencana, dan terukur bagi semua karyawan koperasi. Kinerja karyawan juga sangat berpengaruh besar dalam pengelolaan koperasi (Juniantara, 2015). Mengacu pada surat Keputusan Menteri Koperasi dan UKM No.20/Per/M.KUKM/XI/2015 menyatakan kesehatan koperasi adalah kondisi atau keadaan koperasi yang dinyatakan sehat, cukup sehat, kurang sehat, tidak sehat, dan sangat tidak sehat. Sehat atau tidak sehatnya 
suatu koperasi bisa dilihat dari kriteria skor yang telah ditentukan, seperti pada Tabel 2:

Tabel 2.

Predikat Kesehatan Koperasi

\begin{tabular}{cc}
\hline Skor & Predikat \\
\hline $\mathbf{8 0 - 1 0 0}$ & Sehat \\
$\mathbf{6 0 - 8 0}$ & Cukup Sehat \\
$\mathbf{4 0 - 6 0}$ & Kurang Sehat \\
$\mathbf{2 0 - 4 0}$ & Tidak Sehat \\
$\leq \mathbf{2 0}$ & Sangat Tidak Sehat \\
\hline
\end{tabular}

Sumber: Peraturan Menteri Negara Koperasi dan Usaha Kecil dan Menengah Republik Indonesia No.20/Per/M.KUKM/XI/2015

Sesuai dengan Peraturan Menteri Negara Koperasi dan Usaha Kecil dan Menengah Republik Indonesia No. 20/Per/M.KUKM/XI/2015 tercatat pada tahun 2015 total jumlah koperasi di Kabupaten Tabanan yang dinilai yaitu 101 unit yang berasal dari masing-masing Kecamatan. Koperasi yang dinyatakan sehat sebanyak 16 unit, cukup sehat 84 unit, dan kurang sehat 1 unit. Berdasarkan predikat dan penilaian yang telah ditentukan dari Dinas Koperasi Kota Tabanan Tahun 2015, pencapaian koperasi-koperasi yang dinyatakan sehat tidak terlepas dari tercapainya realisasi anggaran pendapatan karyawan tahun 2015 atau target yang telah ditetapkan sebelumnya. Jumlah koperasi yang dinilai per Kecamatan tahun 2015 dapat ditunjukkan pada Tabel 3. 
Tabel 3.

Jumlah Koperasi yang Dinilai Per Kecamatan Tahun 2015

\begin{tabular}{lcc}
\hline No & Kecamatan & Jumlah \\
\hline $\mathbf{1}$ & Kediri & 16 \\
$\mathbf{2}$ & Tabanan & 25 \\
$\mathbf{3}$ & Penebel & 13 \\
$\mathbf{4}$ & Marga & 16 \\
$\mathbf{5}$ & Baturiti & 6 \\
$\mathbf{6}$ & Kerambitan & 8 \\
$\mathbf{7}$ & Selemadeg & 5 \\
$\mathbf{8}$ & Selemadeg Barat & 5 \\
$\mathbf{9}$ & Selemadeg Timur & 6 \\
$\mathbf{1 0}$ & Pupuan & 1 \\
& Jumlah & $\mathbf{1 0 1}$
\end{tabular}

Sumber: Dinas Koperasi UMKM Kabupaten Tabanan, 2015

Penelitian awal yang dilakukan dan dari wawancara dengan beberapa manajer koperasi di Tabanan diperoleh informasi bahwa masih rendahnya kinerja karyawan koperasi dalam hal pencapain target (kuantitas) yang telah ditetapkan, kurangnya rasa solidaritas atau rasa saling membantu antar karyawan sehingga sering terjadi kesalahan (kerja sama dengan rekan kerja) sehingga menyebabkan waktu kerja menjadi tidak efisien. Rendahnya kinerja karyawan dapat dipengaruhi oleh beberapa faktor yaitu salah satunya ialah gaya kepemimpinan yang diterapkan oleh atasannya.

Subhi (2014) menunjukkan gaya kepemimpinan transformasional berpengaruh positif dan signifikan terhadap kinerja karyawan. Hal ini menunjukkan bahwa semakin baik penerapan gaya kepemimpinan 
transformasional pada karyawan akan membuat mereka memiliki kinerja yang tinggi. Hasil penelitian ini didukung oleh Thamrin (2012) dan Mahendra (2016) yang menunjukkan bahwa terdapat hubungan yang positif dan signifikan antara kepemimpinan transformasional dan kinerja karyawan.

Penurunan kinerja karyawan juga dapat dipengaruhi oleh $O C B$ karyawan. $O C B$ adalah perilaku pilihan yang tidak menjadi bagian dari kewajiban kerja formal seorang karyawan, namun mendukung berfungsinya organisasi tersebut secara efektif (Robbins dan Judge, 2008). Damaryanthi (2016) menunjukkan $O C B$ berpengaruh positif dan signifikan terhadap kinerja karyawan. Karyawan yang memiliki $O C B$ tinggi terhadap tempat ia berkerja maupun pada karyawan lainnya akan memunjukkan kinerja yang meningkat serta sikap yang lebih mudah bergaul, ramah, dan lebih dapat menerima pekerjaan yang ia dapatkan tanpa banyak mengeluh dan membantah. Hasil penelitian ini juga didukung oleh Harwiki (2013) dan Kimbal dkk. (2015).

$O C B$ karyawan juga bisa dipengaruhi oleh kepemimpinan yang diterapkan oleh manajer. Shah et al., (2016) menunjukkan kepemimpinan transformasional berpengaruh positif dan signifikan terhadap $O C B$. Pemimpin transformasional dapat berkontribusi dalam kinerja dan $O C B$ karyawan yang pada akhirnya akan meningkatkan output organisasi karena gaya kepemimpinan transformasional dianggap sebagai faktor penting yang mempengaruhi $O C B$. Hasil penelitian tersebut didukung oleh Lian dan Salleh (2011) dan Sanati dan Nikbakhsh (2014).

Hasil dari penelitian-penelitian sebelumnya menunjukkan $O C B$ juga dapat berperan sebagai variabel mediasi. Chamariyah et al., (2015) menunjukkan $O C B$ 
berpengaruh sebagai variabel mediasi antara kepemimpinan transformasional dan kinerja karyawan. Kinerja karyawan meningkat menjadi maksimal karena dipengaruhi oleh kepemimpinan transformasional dengan $O C B$ sebagai mediasi. Berdasarkan fenomena yang terjadi di lapangan, maka peneliti ingin menguji lebih lanjut pengaruh kepemimpinan transformasional terhadap kinerja karyawan dengan $O C B$ sebagai variabel mediasi untuk mendapatkan hasil yang lebih akurat. Peneliti juga ingin menguji apakah variabel $O C B$ sebagai variabel mediasi absolut atau parsial hubungan antara kepemimpinan transformasional dengan kinerja karyawan koperasi di Tabanan.

\section{Pengaruh Kepemimpinan Transformasional Terhadap Organizational Citizenship Behavior}

Gaya kepemimpinan transformasional mencerminkan sosok pemimpin yang memberikan inspirasi dan motivasi kepada bawahannya serta memberikan perhatian dalam pengembangan diri masing-masing karyawan. Tindakan pemimpin tersebut secara tidak langsung dapat menumbuhkan $O C B$ karyawan dalam menghadapi permasalahan di lingkungan kerja. Pengaruh pemimpin sangat besar dalam menumbuhkan peran ekstra karyawan dalam melakukan pekerjaannya.

Rahmatun dan Anang (2015) menunjukkan gaya kepemimpinan transformasional berpengaruh positif dan signifikan terhadap $O C B$. Semakin tinggi penerapan gaya kepemimpinan transformasional dengan memberikan motivasi, mendorong karyawan lebih berinovasi dan kreatif, serta memperhatikan 
perkembangan dan prestasi kerja karyawan maka akan semakin tinggi pula $O C B$. Saeed dan Sahbaz (2012), Sofiah et al., (2014) juga menunjukkan bahwa terdapat hubungan yang positif dan signifikan antara kepemimpinan transformasional terhadap $O C B$ karyawan. Maka dapat dirumuskan hipotesis sebagai berikut:

H1: Kepemimpinan transformasional berpengaruh positif terhadap organizational citizenship behavior.

\section{Pengaruh Kepemimpinan Transformasional Terhadap Kinerja Karyawan}

Pemimpin memiliki tanggung jawab yang besar untuk menciptakan suatu kondisi yang merangsang anggota agar dapat mencapai tujuan yang ditentukan bersama. Gaya kepemimpinan menjadi cermin kemampuan seseorang dalam mempengaruhi individu atau kelompok dalam bertindak di lingkungan kerja. Pradana dkk. (2010) menunjukkan bahwa kepemimpinan transformasional berpengaruh positif dan signifikan pada kinerja karyawan. Gaya kepemimpinan transformasional mempengaruhi kinerja karyawan karena dengan indikator seperti karisma, inspirasional, perhatian individual serta stimulus intelektual membuat karyawan lebih nyaman dan termotivasi tanpa merasakan tekanan, sehingga karyawan dapat mencapai kinerja yang diinginkan pemimpin. Penelitian ini sesuai dengan hasil Rasool et al., (2015) dan Shafie et al., (2013) yang menunjukkan bahwa terdapat pengaruh yang positif dan signifikan antara kepemimpinan transformasional dan kinerja karyawan. Maka dapat dirumuskan hipotesis sebagai berikut:

$\mathrm{H}_{2}$ : Kepemimpinan transformasional berpengaruh positif terhadap kinerja karyawan 


\section{Pengaruh Organizational Citizenship Behavior Terhadap Kinerja Karyawan}

Robbins dan Judge (2008) menyatakan bahwa, organisasi yang sukses membutuhkan karyawan yang melakukan tugas lebih dari sekedar tugas biasa mereka, yang akan memberikan kinerja melebihi harapan. Fitriastuti (2013) menunjukkan bahwa, $O C B$ mampu meningkatkan kinerja karyawan. Hal ini mengindikasikan, bahwa karyawan telah membentuk perilaku $O C B$ dalam dirinya, dapat dilihat dari sikap karyawan yang berperilaku mengantikan orang lain dalam bekerja, berperilaku melebihi persyaratan minimal, kemauan bertoleransi, terlibat dalam fungsi organisasi dan dapat menyimpan informasi. Perilaku membantu yang ditunjukkan karyawan akan berkontribusi meningkatkan kinerja karyawan. Penelitian serupa dilakukan oleh Darto et al., (2015) dan Karavardar (2014), menunjukkan bahwa $O C B$ berpengaruh positif dan signifikan terhadap kinerja karyawan. Maka dapat dirumuskan hipotesis sebagai berikut:

H3: Organizational citizenship behavior berpengaruh positif terhadap kinerja karyawan.

\section{Pengaruh Kepemimpinan Transformasional Terhadap Kinerja Karyawan dengan Mediasi Organizational Citizenship Behavior}

Manajer dengan kepemimpinan transformasional yang tinggi dapat mengembangkan $O C B$ karyawan yang kemudian dapat berkontribusi terhadap kinerja karyawan. Shah et al., (2016) menunjukkan bahwa kepemimpinan 
transformasional berpengaruh positif dan signifikan terhadap $O C B$. Pemimpin dengan gaya transformasional dapat lebih mempengaruhi $O C B$ karyawan. Pemimpin transformasional dapat mempengaruhi $O C B$ karyawan dan kinerja karyawan yang akhirnya meningkatkan output perusahaan. Gaya kepemimpinan transformasional dianggap sebagai faktor penting yang mempengaruhi $O C B$ yang akan berdampak terhadap kinerja karyawan.

Chamariyah et al., (2015) meneliti tentang kepemimpinan transformasional dan kinerja karyawan dan menemukan kepemimpinan transformasional juga berpengaruh positif terhadap $O C B$. Oleh karena itu, $O C B$ memediasi hubungan antara kepemimpinan transformasional dan kinerja karyawan. Ini mungkin berarti bahwa kinerja karyawan meningkat menjadi maksimal karena dipengaruhi oleh kepemimpinan transformasional dengan $O C B$ sebagai variabel mediasi. Hasil penelitian tersebut didukung oleh penelitian Jung et al., (2007), Vigoda dan Gadot (2007), Warsito (2007) yang menunjukkan bahwa terdapat pengaruh kepemimpinan transformasional terhadap kinerja karyawan yang dimediasi oleh $O C B$

H4: Organizational citizenship behavior memediasi pengaruh kepemimpinan transformasional terhadap kinerja karyawan.

\section{METODE PENELITIAN}

\section{Ruang Lingkup Penelitian}

Penelitian ini dilakukan pada koperasi-koperasi di Tabanan yang dinilai kesehatannya pada tahun 2015. Berdasarkan data koperasi UMKM Kabupaten 
Tabanan (2015), terdapat peningkatan jumlah koperasi di Tabanan dari tahun 2011 (493 koperasi) sampai tahun 2015 (549 koperasi), maka Tabanan dipilih sebagai lokasi penelitian. Subjek penelitian ini yaitu karyawan-karyawan koperasi dan objek yang diteliti yaitu kinerja karyawan, $O C B$, dan kepemimpinan transformasional.

\section{Jenis Data dan Sumber Data}

Penelitian ini menggunakan data kuantitatif yang terdiri atas data perkembangan koperasi (jumlah koperasi, anggota, aset, dan SHU), data jumlah karyawan koperasi di Tabanan. Data kualitatif terdiri atas lokasi penelitian, gambaran umum koperasi, karakteristik responden yang dari jenis kelamin dan pendidikan terakhir karyawan.

Kedua jenis data itu diperoleh dari dua sumber, yaitu sumber primer yang diperoleh dari manajer dan karyawan koperasi. Sumber sekunder yang diperoleh dari Dinas Koperasi Usaha Mikro Kecil dan Menengah Kabupaten Tabanan, serta artikel-artikel studi empiris terkait kinerja karyawan, $O C B$, dan kepemimpinan transformasional.

\section{Variabel Penelitian}

Penelitian ini menggunakan variabel endogen, mediasi dan eksogen. Variabel endogen penelitian ini adalah kepemimpinan transformasional, variabel mediasi penelitian ini adalah organizational citizenship behavior, dan variabel endogen penelitian ini adalah kinerja karyawan.

\section{Populasi dan Sampel}


Populasi dalam penelitian ini adalah seluruh karyawan koperasi di Tabanan yaitu berjumlah 160 karyawan dari 25 koperasi yang dinilai kesehatannya pada tahun 2015. Penilaian kesehatan koperasi di kabupaten Tabanan pada tahun 2015 menunjukkan bahwa koperasi terbanyak yang dinilai berada di kecamatan Tabanan. Koperasi yang tergolong kurang sehat juga berada di kecamatan Tabanan, sehingga sampel dalam penelitian ini mengambil koperasi di kecamatan Tabanan yang dinilai kesehatannya pada tahun 2015.

\section{Metode Penentuan Sampel}

Penentuan ukuran sampel penelitian menggunakan rumus Slovin. Teknik pengambilan sampel yang digunakan adalah acak sederhana (simple random sampling) dengan sampel berjumlah 114 karyawan koperasi di kecamatan Tabanan. Metode undian digunakan dalam proses pengambilan sampel karyawan pada masing-masing koperasi di Tabanan.

\section{Metode Pengumpulan Data}

Metode pengumpulan data menggunakan kuesioner dan wawancara. Kuesioner disebarkan ke 25 koperasi di kecamatan Tabanan dan diisi oleh karyawan dari masing-masing koperasi terkait variabel penelitian. Target sampel telah terpenuhi karena kuesioner yang disebarkan dan kembali sebanyak 114 lembar sesuai dengan seharusnya. Wawancara secara langsung dengan manajer koperasi dan karyawan juga dilakukan untuk mendapatkan informasi.

\section{Teknik Analisis Data}

Penelitian ini menggunakan statistik deskriptif dan statistik inferensial untuk analisis data. Statistik deskriptif digunakan untuk mendeskripsikan data 
demografis responden yang disajikan melalui tabel, perhitungan rata-rata, dan perhitungan persentase, sedangkan statistik inferensial digunakan untuk menguji hipotesis dengan menggunakan teknik analisis SEM-PLS.

\section{HASIL DAN PEMBAHASAN}

\section{Karakteristik Responden}

Karakteristik responden berdasarkan umur menunjukkan dominasi responden yang berumur 26 - 30 tahun (28,9 persen), umur $>40$ tahun $(25,4$ persen), umur 36 - 40 tahun (18,4 persen), umur $<26$ tahun $(14,0$ persen $)$, dan umur 31 - 35 tahun (13,2 persen). Karakteristik responden berdasarkan jenis kelamin menunjukkan dominasi pada responden perempuan (64,9 persen) sedangkan responden laki-laki (35,1 persen). Karakteristik responden berdasarkan jabatan didominasi oleh jabatan kolektor (28,1 persen), jabatan administrasi $(21,1$ persen), jabatan keuangan (15,8 persen), jabatan kasir (13,2 persen), dan karyawan dengan jabatan accounting (21,9 persen).

Karakteristik responden berdasarkan tingkat pendidikan mayoritas berpendidikan SMA (74,6 persen), Diploma (18,4 persen), dan minoritas berpendidikan S1 (7,0 persen). Karakteristik responden yang terakhir yaitu masa kerja dengan mayoritas memiliki masa kerja 3 - 7 tahun (43,9 persen), responden dengan masa kerja $8-12$ tahun $(32,5$ persen $)$, responden dengan masa kerja $<3$ tahun (12,3 persen), dan responden paling sedikit dengan masa kerja $13-17$ tahun (11,4 persen). 
ISSN : 2337-3067

E-Jurnal Ekonomi dan Bisnis Universitas Udayana 6.7 (2017): 2761-2788

\section{Hasil Pengujian Outer Model}

Hasil uji outer model menunjukkan bahwa seluruh indikator variabel dapat dikatakan valid dan reliabel, berikut adalah rinciannya pada Tabel 4.

Tabel 4.

Uji Outer Model

\begin{tabular}{|c|c|c|c|c|c|}
\hline & Variabel dan Indikatornya & $\begin{array}{c}\text { Outer } \\
\text { Loadings } \\
*)\end{array}$ & $\begin{array}{c}A V E \\
*)\end{array}$ & $\begin{array}{c}\text { Composite } \\
\text { Reliability } \\
* *)\end{array}$ & $\begin{array}{c}\text { Cronbach } \\
\text { Alpha } \\
* *)\end{array}$ \\
\hline $\mathbf{Y}$ & KINERJA KARYAWAN & & 0,599 & 0,930 & 0,915 \\
\hline Y1 & Kualitas Kerja & & & & \\
\hline Y1.1 & $\begin{array}{l}\text { Pekerjaan karyawan sesuai dengan } \\
\text { SOP }\end{array}$ & 0,817 & & & \\
\hline $\mathrm{Y} 1.2$ & Hasil kerja karyawan terpercaya & 0,817 & & & \\
\hline $\mathrm{Y} 1.3$ & Hasil kerja karyawan terpercaya & 0,833 & & & \\
\hline Y2 & $\begin{array}{l}\text { Kuantitas Kerja } \\
\text { Mampu mengerjakan pekerjaan }\end{array}$ & & & & \\
\hline Y2.1 & $\begin{array}{l}\text { sesuai dengan kuantitas yang } \\
\text { ditetapkan }\end{array}$ & 0,901 & & & \\
\hline $\mathrm{Y} 2.2$ & $\begin{array}{l}\text { Jumlah/ Volume pekerjaan sesuai } \\
\text { dengan harapan organisasi }\end{array}$ & 0,910 & & & \\
\hline Y3 & Waktu Kerja & & & & \\
\hline Y3.1 & $\begin{array}{l}\text { Menyelesaikan pekerjaan tepat } \\
\text { waktu }\end{array}$ & 0,896 & & & \\
\hline $\mathrm{Y} 3.2$ & $\begin{array}{l}\text { Mempergunakan waktu secara } \\
\text { efektif }\end{array}$ & 0,879 & & & \\
\hline Y4 & Kerja Sama dengan Rekan Kerja & & & & \\
\hline Y4.1 & $\begin{array}{l}\text { Mampu bekerja sama dengan rekan } \\
\text { kerja }\end{array}$ & 0,932 & & & \\
\hline Y4.2 & $\begin{array}{l}\text { Bersikap positif salam setiap } \\
\text { pekerjaan kelompok }\end{array}$ & 0,917 & & & \\
\hline M & $\begin{array}{l}\text { ORGANIZATIONAL } \\
\text { CITIZENSHIP BEHAVIOR }\end{array}$ & & 0,542 & 0,966 & 0,963 \\
\hline M1 & Altruisme & & & & \\
\hline M1.1 & $\begin{array}{l}\text { Membantu rekan kerja yang beban } \\
\text { kerjanya berlebih }\end{array}$ & 0.817 & & & \\
\hline M1.2 & $\begin{array}{l}\text { Menggantikan pekerjaan rekan } \\
\text { kerja yang berhalangan hadir }\end{array}$ & 0.862 & & & \\
\hline M1.3 & $\begin{array}{l}\text { Membantu rekan kerja yang } \\
\text { memiliki masalah dengan pekerjaan }\end{array}$ & 0.83 & & & \\
\hline M1.4 & $\begin{array}{l}\text { Membantu rekan kerja agar lebih } \\
\text { produktif }\end{array}$ & 0.902 & & & \\
\hline M1.5 & $\begin{array}{l}\text { Membantu proses orientasi } \\
\text { lingkungan kerja kepada pegawai }\end{array}$ & 0.751 & & & \\
\hline
\end{tabular}


baru

\section{M2 Conscientiousness}

M2.1 Melapor kepada atasan terlebih dahulu bila tidak masuk kerja

Menyelesaikan tugas sebelum waktunya

Berusaha melakukan lebih dari apa yang seharusnya dilakukan Sukarela melakukan sesuatu yang

M2.4 bermanfaat bagi organisasi disamping tugas utama

M2.5 Tidak membuang-buang waktu kerja

M2.6 Tidak mengambil waktu istirahat secara berlebihan

M2.7 Mematuhi peraturan meski tidak diawasi

\section{M3 Courtesy}

M3.1 Menghormati privasi rekan kerja

M3.2 Tidak membuat masalah dengan

M3.3 Menghindari terjadinya perselisihan antar rekan kerja Mempertimbangkan dampak

M3.4 terhadap rekan kerja dari setiap tindakan yang dilakukan Berkonsultasi terlebih dahulu

M3.5 dengan rekan kerja yang mungkin akan berpengaruh terhadap tindakan yang dilakukan

M4 Civic Virtue

M4.1 Peduli terhadap perkembangan yang terjadi pada organisasi

M4.2 Ikut serta dalam berbagai kegiatan
yang diselenggarakan organisasi

M4.3 Memberikan saran inovatif untuk meningkatkan kualitas organisasi

M5 Sportmanship

M5.1 Tidak mengeluh atas permasalahan yang sepele Menerima setiap kebijakan yang

M5.3 ditetapkan organisasi

$\mathrm{X} 1 \quad$ Idealized Influence

X1.1 Komitmen

X1.2 Konsisten terhadap keputusan 
$\begin{array}{lll}\text { X2.1 } & \begin{array}{l}\text { Memotivasi agar sesuai visi, misi } \\ \text { dan tujuan organisasi }\end{array} & 0.89\end{array}$

X2.2 Memotivasi agar sesuai prosedur $\quad 0.894$

X2.2 kerja

X2.3 $\begin{array}{ll}\text { Mengarahkan untuk sesuai } & 0.927 \\ \text { mekanisme kerja }\end{array}$

X3 Intellectual Stimulation

X3.1 Inspirasi kreatif 0.864

X3.2 Mendorong untuk inovatif 0.792

X3.3 Perhatian untuk peningkatan kinerja 0.904

X4 Individualized Consideration

X4.1 Perhatian pada profesionalitas $\quad 0.920$

X4.2 Perhatian dalam karir 0.926

Sumber: Hasil pengolahan data, 2016

Catatan: *) indikator valid jika outer loadings dan $A V E>0,50$

**) indikator reliabel jika composite reliability dan cronbach alpha $>0,70$

\section{Hasil Pengujian Inner Model}

Hasil uji inner model dapat dilihat dari nilai $R$-square pada Tabel 5 berikut yang merupakan uji goodness of fit model. Berdasarkan Tabel 5, dapat dijelaskan bahwa seluruh konstruk endogen memiliki nilai $R$-square diatas 0,67 , yang mengindikasikan bahwa konstruk eksogen memiliki pengaruh yang substantif terhadap konstruk endogen.

Tabel 5.

R-square

\begin{tabular}{cc}
\hline Variabel Endogen & R-square \\
\hline Kinerja Karyawan (Y) & 0,719 \\
Organizational Citizenship Behavior $(\mathrm{M})$ & 0,605 \\
\hline Sumber: Hasil pengolahan data, 2016 &
\end{tabular}

Untuk mengukur seberapa baik nilai observasi dihasilkan oleh model dan juga estimasi parameternya, maka perlu menghitung $Q^{2}$ sebagai berikut:

$$
\begin{aligned}
\mathrm{Q}^{2} & =1-\left(1-\left(\mathrm{R}_{1}\right)^{2}\right)\left(1-\left(\mathrm{R}_{2}\right)^{2}\right) \\
& =1-(1-(0,719)(1-(0,605) \\
& =1-(0,281)(0,395)
\end{aligned}
$$




$$
\begin{aligned}
& =1-0,111 \\
& =0,889
\end{aligned}
$$

Besaran $\mathrm{Q}^{2}$ memiliki nilai dengan rentang $0<\mathrm{Q}^{2}<1$, dimana semakin mendekati 1 berarti model semakin baik. Hasil perhitungan tersebut didapat nilai $\mathrm{Q}^{2}$ adalah sebesar 0,889 , sehingga dapat disimpulkan bahwa model memiliki predictive relevance yang baik $\left(\mathrm{Q}^{2}=0,889>0\right)$.

\section{Hasil Pengujian Pengaruh Langsung}

Penelitian ini menggunakan pendekatan analisis Partial Least Square (PLS) untuk melakukan uji dan analisis terhadap hipotesis penelitian yang telah dikemukakan sebelumnya. Gambar 1 berikut adalah struktur hubungan kausal hasil analisis Partial Least Square.

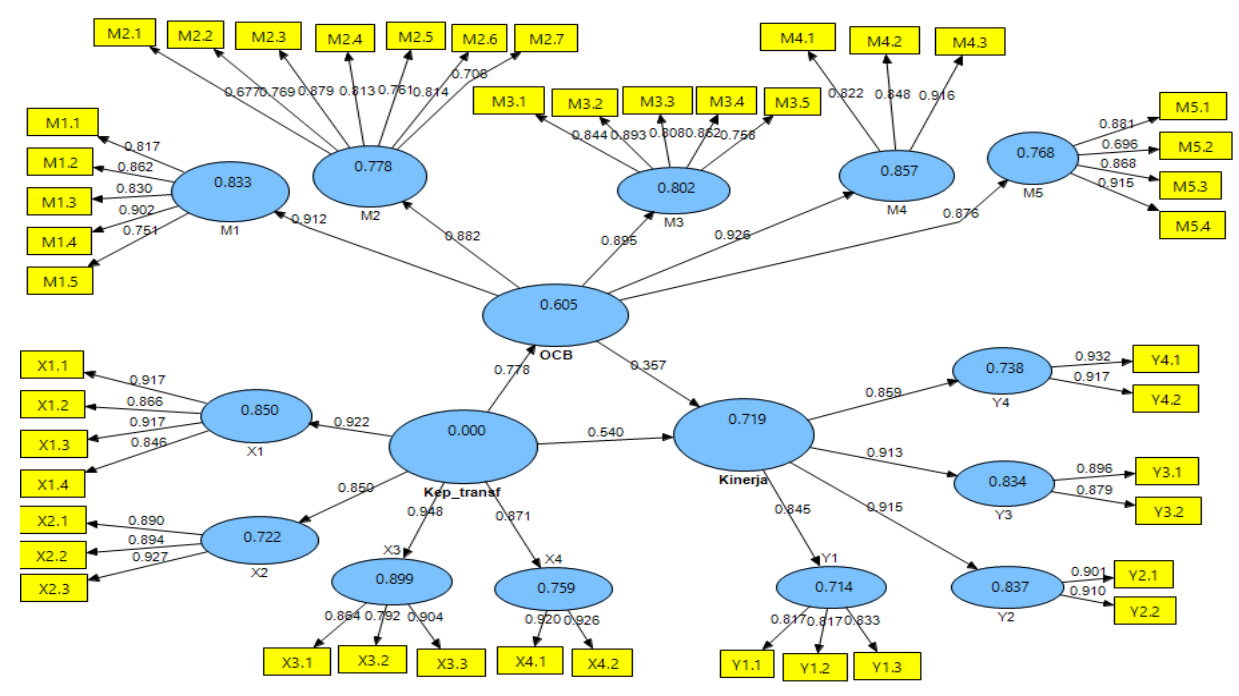

Gambar 1.

Hasil Output PLS

Berdasarkan Tabel 6, dapat disimpulkan bahwa kepemimpinan transformasional berpengaruh langsung terhadap organizational citizenship behavior dengan koefisien korelasi sebesar 0,778 dan nilai T-statistik sebesar 12,934 (nilai T-statistik > T-kritis 1,96), kepemimpinan transformasional 
berpengaruh langsung terhadap kinerja karyawan dengan koefisien korelasi sebesar 0,540 dan nilai T-statistik sebesar 5,040 (nilai T-statistik > T-kritis 1,96), serta organizational citizenship behavior berpengaruh langsung terhadap kinerja karyawan dengan koefisien korelasi sebesar 0,357 dan nilai T-statistik sebesar 3,418 (nilai T-statistik > T-kritis 1,96).

Tabel 6.

Path Coefficients

\begin{tabular}{lccc}
\hline \multicolumn{1}{c}{ Korelasi Antar Konstruk } & Koefisien Korelasi & t-Statistics & Keterangan \\
\hline $\begin{array}{l}\text { Kepemimpinan Transformasional (X) } \\
\begin{array}{l}\rightarrow \text { Organizational Citizenship } \\
\text { Behavior (M) }\end{array}\end{array}$ & 0,778 & 12,934 & Signifikan \\
$\begin{array}{l}\text { Kepemimpinan Transformasional (X) } \\
\rightarrow \text { Kinerja Karyawan (Y) }\end{array}$ & 0,540 & 5,040 & Signifikan \\
$\begin{array}{l}\text { Organizational Citizenship Behavior } \\
(\mathrm{M}) \rightarrow \text { Kinerja Karyawan (Y) }\end{array}$ & 0,357 & 3,418 & Signifikan \\
\hline Sumber: Hasil pengolahan data, 2016 & & &
\end{tabular}

\section{Hasil Pengujian Pengaruh Mediasi}

Berdasarkan pada Tabel 6, dapat dilakukan uji peran mediasi organizational citizenship behavior pada pengaruh kepemimpinan transformsional terhadap kinerja karyawan dengan memeriksa koefisien pengaruh langsung variabel independen terhadap variabel dependen pada model dengan melibatkan variabel mediasi. 


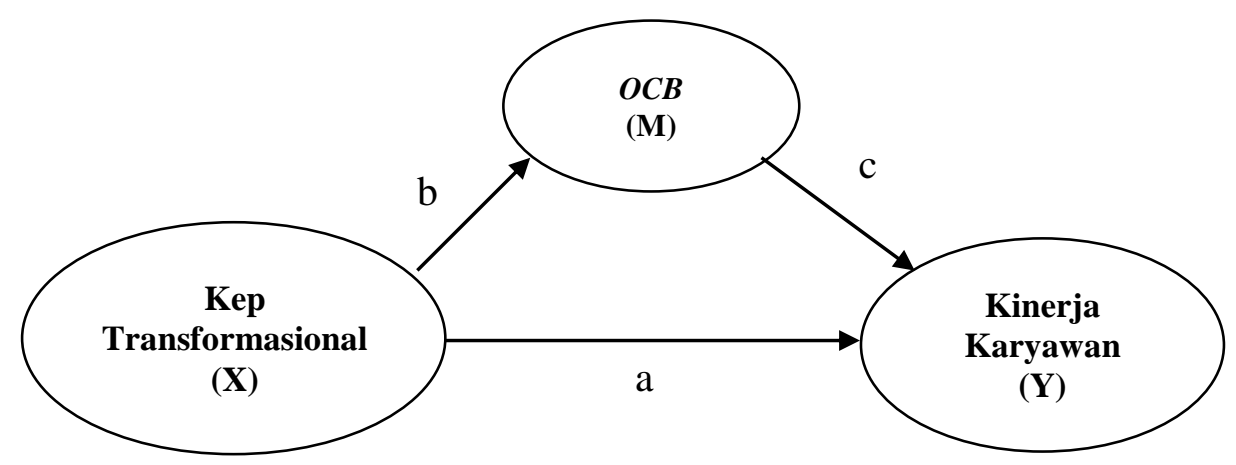

Gambar 2.

Diagram Alur

Hasil pemeriksaan uji mediasi berdasarkan Gambar 2, telah menunjukkan bahwa pengaruh variabel independen terhadap variabel mediasi (b) adalah signifikan, pengaruh variabel mediasi terhadap variabel dependen (c) adalah signifikan, pengaruh langsung variabel independen terhadap variabel dependen pada model dengan melibatkan variabel mediasi (a) adalah signifikan, maka dikatakan sebagai mediasi sebagian (partial mediation). Dengan demikian, organizational citizenship behavior memediasi sebagian (partial mediation) pengaruh kepemimpinan transformasional terhadap kinerja karyawan.

Pengaruh kepemimpinan transformasional terhadap organizational citizenship behavior adalah positif dan signifikan (T-statistik 12,934 > 1,96), pengaruh organizational citizenship behavior terhadap kinerja karyawan adalah positif dan signifikan (T-statistik $3,418>1,96)$ dan pengaruh langsung kepemimpinan transformasional terhadap kinerja karyawan adalah positif dan signifikan (T-statistik 5,040 > 1,96), maka dapat disimpulkan organizational citizenship behavior berperan sebagai pemediasi parsial (partial mediation) antara pengaruh kepemimpinan transformasional terhadap kinerja karyawan. Hal ini 
memiliki makna bahwa memediasi bisa dengan 2 cara yaitu melalui kepemimpinan transformasional dan melalui $O C B$.

\section{Pengaruh Kepemimpinan Transformasional Terhadap Organizational Citizenship Behavior}

Hasil pengujian hipotesis membuktikan bahwa kepemimpinan transformasional berpengaruh positif dan signifikan terhadap organizational citizenship behavior. Hal ini menunjukkan bahwa semakin baik intensitas penerapan kepemimpinan transformasional manajer koperasi - koperasi di Tabanan maka akan semakin tinggi pula tingkat $O C B$ karyawan yang ada di koperasi tersebut. Begitu pula sebaliknya, semakin buruk intensitas penerapan kepemimpinan transformasional manajer koperasi - koperasi di Tabanan maka semakin rendah tingkat $O C B$ karyawan pada koperasi tersebut.

Penelitian ini mendukung hasil penelitian sebelumnya dan konsisten dengan hasil penelitian Rahmatun dan Anang (2015), Saeed dan Sahbaz (2012), Sofiah et al., (2014), dan Jha (2013) yang menunjukkan bahwa kepemimpinan transformasional memberikan pengaruh yang positif dan signifikan terhadap $O C B$. Dengan demikian, hipotesis kepemimpinan transformasional berpengaruh positif dan signifikan terhadap $O C B$ dapat diterima.

\section{Pengaruh Kepemimpinan Transformasional Terhadap Kinerja Karyawan}

Hasil pengujian hipotesis membuktikan bahwa kepemimpinan transformasional berpengaruh positif dan signifikan terhadap kinerja karyawan. Hal ini menunjukkan bahwa semakin baik gaya kepemimpinan transformasional manajer koperasi di Tabanan maka akan semakin tinggi pula kinerja karyawan 
koperasi tersebut. Apabila intensitas penerapan kepemimpinan transformasional oleh manajer koperasi di Tabanan ditingkatkan, maka akan mampu memberikan kontribusi yang signifikan untuk meningkatkan persepsi karyawan dalam meningkatkan kinerjanya dalam hal memotivasi dan memberikan inspirasi kepada karyawan.

Penelitian ini mendukung hasil penelitian sebelumnya dan konsisten dengan hasil penelitian Rasool et al., (2015), Shafie et al., (2013), Risambessy et al., (2012), dan Pradana dkk. (2010) menunjukkan bahwa kepemimpinan transformasional memberikan pengaruh yang positif dan signifikan terhadap kinerja karyawan. Dengan demikian, hipotesis kepemimpinan transformasional berpengaruh positif dan signifikan terhadap kinerja karyawan dapat diterima.

\section{Pengaruh Organizational Citizenship Behavior Terhadap Kinerja Karyawan}

Hasil pengujian hipotesis membuktikan bahwa organizational citizenship behavior berpengaruh positif dan signifikan terhadap kinerja karyawan. Hal ini menunjukkan bahwa semakin tinggi peran ekstra yang dimiliki oleh karyawankaryawan koperasi di Tabanan maka akan semakin tinggi pula niat karyawan tersebut untuk meningkatkan kinerja. Temuan ini dapat diartikan bahwa apabila $O C B$ (peran ekstra) ditingkatkan oleh karyawan koperasi-koperasi di Tabanan, maka prilaku tersebut akan mampu memberikan kontribusi yang signifikan terhadap peningkatan kinerja karyawan juga.

Penelitian ini mendukung hasil penelitian sebelumnya dan konsisten dengan hasil penelitian Fitrianasari (2013), Darto et al., (2015), Karavardar 
(2014), dan Fitriastuti (2013) menunjukkan bahwa $O C B$ memberikan pengaruh yang positif dan signifikan terhadap kinerja karyawan. Dengan demikian, hipotesis $O C B$ berpengaruh positif dan signifikan terhadap kinerja karyawan dapat diterima.

\section{Pengaruh Kepemimpinan Transformasional Terhadap Kinerja Karyawan dengan Mediasi Organizational Citizenship Behavior}

Hasil pengujian hipotesis membuktikan bahwa kepemimpinan transformasional berpengaruh positif dan signifikan terhadap $O C B, O C B$ berpengaruh positif dan signifikan terhadap kinerja karyawan, dan kepemimpinan transformasional berpengaruh positif dan signifikan terhadap kinerja karyawan dengan mediasi $O C B$. Hasil ini menunjukkan bahwa memediasi bisa dengan 2 cara yaitu melalui kepemimpinan transformasional dan melalui $O C B$. Kepemimpinan transformasional yang diterapkan pemimpin koperasi di Tabanan secara nyata dapat mempengaruhi $O C B$ karyawan dan kinerja karyawan koperasi. Perilaku peran ekstra $(O C B)$ karyawan koperasi secara nyata juga dapat mempengaruhi kinerja.

Hasil ini mendukung beberapa hasil penelitian sebelumnya dan konsisten dengan hasil penelitian Chamariyah et al., (2015), Jung et al., (2007), Vigoda dan Gadot (2007), Warsito (2007) yang menunjukkan bahwa $O C B$ memediasi pengaruh kepemimpinan transformasional terhadap kinerja karyawan.

\section{Implikasi Teoritis}

Berdasarkan hasil yang telah dipaparkan, kepemimpinan transformasional terbukti memiliki pengaruh signifikan terhadap $O C B$, Kepemimpinan 
transformasional secara positif berpengaruh signifikan terhadap kinerja karyawan, $O C B$ berpengaruh positif dan signifikan terhadap kinerja karyawan, serta Kepemimpinan transformasional berpengaruh positif dan signifikan terhadap kinerja karyawan melalui pemediasi parsial organizational citizenship behavior.

Teori Leader- Member Exchange (Organ, 1988) menyatakan bahwa “perilaku karyawan terhadap perusahaan mempunyai peran penting terhadap keberhasilan sebuah organisasi. Perlakuan yang baik terhadap karyawan akan mampu menciptakan perasaan suka rela pada diri karyawan untuk bisa berkorban bagi perusahaan. Aplikasi teori tersebut telah terbukti dalam penerapannya pada koperasi di Tabanan. Peran pemimpin sangat penting dalam memberikan motivasi, inspirasi dan perhatian kepada karyawan sehingga dapat menumbuhkan $O C B$ dan meningkatkan kinerja karyawan. Berdasarkan temuan tersebut, maka hasil penelitian ini mampu menjadi bukti empiris dan mendukung studi-studi empiris lainnya terkait dengan kepemimpinan transformasional, $O C B$, dan kinerja karyawan pada koperasi.

\section{Implikasi Praktis}

Hasil survei menunjukkan bahwa penerapan gaya kepemimpinan transformasional oleh manajer menjadi faktor penting dalam meningkatkan $O C B$ dan kinerja karyawan koperasi di Tabanan. Dimensi inspiration motivation menjadi faktor penting penerapan gaya kepemimpinan transformasional oleh manajer dalam menumbuhkan $O C B$ dan meningkatkan kinerja karyawan. Manajer-manajer koperasi di Tabanan telah mampu memberikan motivasi agar karyawan bekerja sesuai dengan visi, misi, tujuan organisasi serta mampu 
mengarahkan karyawan agar bekerja sesuai dengan mekanisme kerja. Hasil survei menunjukkan dimensi courtesy (kebaikan) dalam $O C B$ merupakan faktor yang penting untuk dilakukan oleh karyawan koperasi di Tabanan untuk meningkatkan kinerja mereka. Karyawan koperasi Tabanan telah mampu menerapkan perilakuperilaku kebaikan pada rekan kerja dan koperasi. Perilaku karyawan yang menghormati privasi rekan kerja, tidak membuat masalah dengan rekan kerja dan menghindari terjadinya perselisihan dengan rekan kerja secara nyata mampu meningkatkan kinerja karyawan koperasi di Tabanan.

\section{SIMPULAN DAN SARAN}

Berdasarkan hasil pembahasan penelitian yang telah dilakukan, maka dapat disimpulkan bahwa: Kepemimpinan transformasional berpengaruh positif dan signifikan terhadap $O C B$. Hal ini berarti bahwa semakin tinggi nilai-nilai kepemimpinan transformasional yang telah diterapkan oleh manajer koperasikoperasi di Tabanan, maka akan semakin tinggi pula $O C B$ karyawan yang ada di koperasi-koperasi di Tabanan. Kepemimpinan transformasional berpengaruh positif dan signifikan terhadap kinerja karyawan. Hal ini berarti bahwa semakin baik penerapan nilai-nilai kepemimpinan transformasional yang ditunjukkan oleh manajer koperasi-koperasi di Tabanan, maka akan semakin baik pula kinerja karyawan koperasi-koperasi di Tabanan. Organizational citizenship behavior berpengaruh positif dan signifikan terhadap kinerja karyawan. Hal ini berarti bahwa semakin tinggi peran ekstra yang dimiliki oleh karyawan koperasi-koperasi di Tabanan, maka akan semakin tinggi pula niat karyawan tersebut untuk 
meningkatkan kinerjanya. Organizational citizenship behavior memediasi pengaruh kepemimpinan transformasional terhadap kinerja karyawan. $O C B$ karyawan akan menguatkan pengaruh kepemimpinan transformasional terhadap kinerja karyawan koperasi di Tabanan.

Saran yang dapat diberikan berdasarkan kesimpulan yang didapat adalah sebagai berikut: Peningkatkan kinerja karyawan sebaiknya kepemimpinan transformasional harus lebih diutamakan oleh manajer karena berdasarkan hasil penelitian bahwa variabel kepemimpinan transformasional mempunyai pengaruh yang besar terhadap kinerja karyawan. Mengacu pada persepsi responden terhadap kepemimpinan transformasional, hendaknya pimpinan selalu memberikan dorongan kepada karyawan agar bekerja sesuai dengan visi, misi, tujuan organisasi kemudian memotivasi karyawan agar bekerja sesuai dengan prosedur kerja dan mengarahkan karyawan agar sesuai dengan mekanisme kerja. Karena pada kasus ini perilaku tersebut paling dominan dalam membentuk konstruk kepemimpinan transformasional. Organizational citizenship behavior terbukti dapat memediasi parsial hubungan antara gaya kepemimpinan transformasional terhadap kinerja karyawan, sehingga disarankan kepada karyawan untuk lebih meningkatkan dan memperhatikan peran ekstranya terhadap organisasi karena hal tersebut bisa meningkatkan kinerja karyawan. Artinya karyawan ikut berpartisipasi aktif dan ikut ambil bagian di dalam organisasi sehingga hal tersebut dapat menunjukkan bagaimana kinerja karyawan di dalam organisasi. Penelitian yang akan datang agar mempertimbangkan faktor - faktor lain yang berpengaruh terhadap kinerja karyawan seperti: motivasi, kepuasan 
kerja, dan sistem reward serta variabel-variabel mediasi lainnya yang mempengaruhi hubungan antara kepemimpinan transformasional dan kinerja karyawan. Selain itu penelitian ini juga dapat memperluas orientasi penelitian dalam lingkup organisasi yang lebih besar atau populasi yang lebih luas, melakukan penelitian pada koperasi di daerah lain sehingga temuan penelitian ini mungkin berbeda dibandingkan dengan penelitian di daerah lain.

\section{REFERENSI}

Juniantara, W. 2015. Pengaruh motivasi dan kepuasan kerja terhadap kinerja karyawan koperasi di Denpasar. E-Jurnal Ekonomi dan Bisnis Universitas Udayana, pp. 611-627.

Subhi, E. R. 2014. Pengaruh kepemimpinan transformasional terhadap kinerja karyawan dengan penghargaan sebagai variabel moderating. Jurnal Ilmu \& Riset Manajemen, Vol 3, No 2, hal. 2-18.

Thamrin, H. M. 2012. The influence of transformational leadership and organizational commitment on job satisfaction and employee performance. International Journal of Innovation Management and Technology, Vol 3, No 5, pp. 566-572.

Mahendra, K. 2016. Pengaruh kepemimpinan transformasional dan $O C B$ terhadap kinerja karyawan dengan mediasi komitmen organisasi pada PT BPR Jaya Kerti. E-jurnal Manajemen Unud, Vol 5, No 5, hal. 2885-2917.

Robbins, S. P., dan Judge. 2008. Perilaku Organisasi: Organizational Behaviour, Edisi 12. Jakarta: Salemba Empat.

Damaryanthi, A. A. Inten. 2016. Pengaruh kecerdasan emosional, komitmen organisasi, dan organizational citizenship behavior terhadap kinerja pegawai FEB. E-Jurnal Manajemen Unud, Vol 5, No 2, hal. 790-820.

Harwiki, W. 2013. The influence of servant leadership on organization culture, organizational commitment, organizational citizenship behavior and employees' performance (study of outstanding cooperatives in East Java Province, Indonesia). Journal of Economics and Behavioral Studies, Vol 5, No 12, pp. 876-885.

Kimbal, F., G. M. Sendow dan D. J. Adare. 2015. Beban Kerja, Organizational Citizenship Behavior, dan Keterlibatan Kerja Pengaruhnya terhadap 
Kinerja Karyawan PT PLN (Persero) Wilayah Suluttenggo Area Manado. Jurnal Emba, Vol 3, No 2, hal. 1061-1072.

Shah, S. M. M., K. B. A. Hamid., P. A. Memon., and M. A. Mirani. 2016. The relationship between transformational leadership and organizational citizenship behavior: an empirical evidence from the banking sector of Pakistan. The International Journal of Business \& Management, Vol 4, No 2, pp. 103-108.

Lian, L. K., and A. L. Salleh. 2011. Mediating effects of subordinates' competence on leadership styles and organisational citizenship behavior. African Journal of Business Management, Vol 5, No 19, pp. 7790-7801.

Sanati, S. S., dan R. Nikbakhsh. 2014. The Relationship between Transformational Leadership Style and Organization Citizenship Behavior in Physical Education Experts in University of Applied Science and Technology in Iran. International Journal of Sport Studies, Vol 4, No 11, pp. 1436-1441.

Chamariyah. A. S., Noermijati and Rofiaty. 2015. The effect of transformational leadership to organizational citizenship behavior $(O C B)$ and employees' performance (study case to PT PLN (Persero) Pamekasan Area). International Journal of Business and Behavioral Sciences, Vol 5, No 4, pp. 1-9.

Rahmatun, T. A., dan A. Kistyanto. 2014. Pengaruh gaya kepemimpinan transformasional dan komitmen organisasi terhadap organizational citizenship behaviour. Jurnal Ilmu Manajemen, Vol 2, No 1, hal. 37-49.

Saeed, A., and S. Ahmad. 2012. Perceived transformational leadership style and organizational citizenship behavior: a case study of administrative staff of university of the Punjab. European Journal of Business and Management, Vol 4, No 21, pp. 150-158.

Sofiah. P., dan Gengeswari. 2014. A study on organizational citizenship behavior in banking industry. International Journal for Innovation Education and Research, Vol 2, No 7, pp. 73-82.

Pradana, M. Andy., B. S. S. Haryo., dan D. Hamid. 2013. Pengaruh gaya kepemimpinan transformasional dan transaksional terhadap kinerja karyawan studi pada karyawan tetap PT. Mustika Bahana Jaya, Lumajang.

Rasool, H. F., I. U. Arfeen.,W. Mothi., and U. Aslam. 2015. Leadership styles and its impact on employee's performance in health sector of Pakistan. City University Research Journal, Vol 5, No 1, pp. 97-109. 
Shafie, B., S. Baghersalimi., and V. Barghi. 2013. The relationship between leadership style and employee performance (case study of real estate registration organization of Tehran province). Singaporean Journal of Business Economics and Management Studies, Vol 2, No 5, pp. 21-28.

Fitriastuti, T. 2013. Pengaruh kecerdasan emosional, komitmen organisasional dan organizational citizenship behavior terhadap kinerja karyawan. Jurnal Dinamika Manajemen, Vol 4, No 2, hal. 103-114.

Darto, M., D. Setyadi., S. S. Riadi., and S. Hariyadi. 2015. The effect of transformational leadership, religiosity, job satisfaction and organizational culture on organizational citizenship behavior and employee performance in the regional offices of national institute of public administration, Republic of Indonesia. European Journal of Business and Management, Vol 7, No 23, pp. 205-219.

Karavardar, G. 2014. Perceived organizational support, psychological empowerment, organizational citizenship behavior, job performance and job embeddedness: a research on the fast food industry in Istanbul, Turkey. International Journal of Business and Management; Vol 9, No 4, pp. 131-139.

Jung, J. Y., and S. Hong. 2008. Organizational citizenship behavior (ocb), TQM and performance at the Maquiladora. International Journal of Quality and Reliability Management, Vol 25, No 8, pp. 793-808.

Vigoda, E., and E. Gadot. 2007. Leadership style, organizational politics and employees' performance, an empirical examination of two competing models. Emerald Group Publishing Limited.

Warsito, B. 2007. Influence of organizational culture and working environment organizational citizenship behavior, motivation and performance (studies in employee rated hotel in Malang and Batu). Brawijaya University Desertation.

Jha, S. 2014. Transformational leadership and psychological empowerment determinants of organizational citizenship behavior. South Asian Journal of Global Business Research, Vol 3, No 1, pp. 18-35.

Shafie, B., S. Baghersalimi., and V. Barghi. 2013. The relationship between leadership style and employee performance (case study of real estate registration organization of Tehran province). Singaporean Journal of Business Economics and Management Studies, Vol 2, No 5, pp. 21-28. 
Risambesy, A., B. Swasto., A. Toyib., dan E. S. Astuti. 2012. The influence of transformation leadership style, motivation, burnout, toward job satisfaction and employee performance. Journal of Basic and Applied Scientific Research, Vol 2, No 9, pp. 33-42.

Fitrianasari, D., U. Nimran dan H. N. Utami. 2013. Pengaruh kompensasi dan kepuasan kerja terhadap organizational citizenship behavior $(O C B)$ dan kinerja karyawan (studi pada perawat Rumah Sakit Umum "Darmayu" di Kabupaten Ponorogo"). Jurnal Profit, Vol 7, No 1, hal. 12-24 